\title{
Isolation and Bioactivities of the Flavonoids Morin and Morin-3-O- $\beta$-D-glucopyranoside from Acridocarpus orientalis-A Wild Arabian Medicinal Plant
}

\author{
Javid Hussain 1,2,*, Liaqat Ali ${ }^{2}$, Abdul Latif Khan ${ }^{2}$, Najeeb Ur Rehman ${ }^{2}$, Farah Jabeen ${ }^{2}$, \\ Jong-Sang Kim ${ }^{3}$ and Ahmed Al-Harrasi ${ }^{1,2, *}$
}

1 Department of Biological Sciences and Chemistry, College of Arts and Sciences, University of Nizwa, Birkat Al-Mouz, Nizwa 616, Oman

2 UoN Chair of Oman's Medicinal Plants and Marine Natural Products, University of Nizwa, Birkat Al-Mouz, Nizwa 616, Oman; E-Mails: malikhejric@gmail.com (L.A.); abdullatif@unizwa.edu.om (A.L.K.); najeeb@unizwa.edu.om (N.U.R.); fjabeen2009@yahoo.com (F.J.)

3 School of Food Science and Biotechnology, Kyungpook National University, Daegu 702-701, Korea; E-Mail: jongsangkim@gmail.com

* Authors to whom correspondence should be addressed; E-Mails: javidhej@unizwa.edu.om (J.H.); aharrasi@unizwa.edu.om (A.A.-H.); Tel.: +968-2544-6705 (J.H.); +968-2544-6328 (A.A.-H.); Fax: +968-2544-6289 (A.A.-H.).

External Editor: Derek J. McPhee

Received: 10 July 2014; in revised form: 20 October 2014 / Accepted: 21 October 2014 /

Published: 31 October 2014

\begin{abstract}
Acridocarpus orientalis is an important medicinal plant for some of the locals of Arabian region. Very little is known about its phytochemical constituents. In the present study, we aimed to isolate bioactive chemicals from the crude methanolic extract of the aerial parts of $A$. orientalis. The extraction and isolation resulted in the purification of two flavonoids: morin (1) and morin-3-O- $\beta$-D-glucopyranoside (2). The structure elucidation was carried out by extensive analysis of spectroscopic data and comparison with the reported data for the known constituents. The pure isolates were subjected to various biological assays for their bioactivities. The compounds $\mathbf{1}$ and $\mathbf{2}$ were significantly active against the growth of various pathogenic fungi and phytotoxic against lettuce seed at higher concentrations. Furthermore, the free radical scavenging activities, anti-lipid peroxidation,
\end{abstract}


and cytotoxic effects against HepG2, HT29, and HCT116 cancer cell lines were also assayed and the results are presented in this paper.

Keywords: flavonoid; morin; Acridocarpus orientalis; Malpighiaceae; antioxidant; lipid peroxidation; cytotoxicity

\section{Introduction}

Plants are the major source of active chemical constituents against diseases [1]. Most of the world's population still relies on the folk medicines for the treatment of a large number of serious diseases. The biologically active principles of medicinal plants include flavonoids, phenolics, and polyphenols with promising anticancer and antioxidant activities [2,3]. Acridocarpus orientalis A. Juss. belongs to the family Malpighiaceae. This is a family of flowering plants found mainly in tropical, Mediterranean, and sandy regions of Asia, Africa and some other Gulf countries, including Oman [4,5]. Several Acridocarpus species are traditionally used as folk medicines all over the world. In addition to the medicinal advantages, some species have been reported to possess many ecological advantages as well. The plants of $A$. socotranus are also used in the traditional medicine system of Yemen as a cure for muscle pain and headaches [6,7]. Acridocarpus chloropterus leaves and stem are reported to have antiplasmodial, antileishmanial and antitrypanosomal activities and are found mainly in Tanzania [8]. A. orientalis has been reported mainly from the border areas of UAE and Oman, where it is used for the treatment of muscle pain, headaches, paralysis, tendon and joint pains as well as to treat the udder inflammation in cattle [6,7]. The use of $A$. orientalis against inflammatory diseases suggests further utility as a way to treat cancer [9], but $A$. orientalis has not been previously studied for its role against oxidative stress and cancerous cells.

Based on the above mentioned potential of the plant in the biological and pharmacological field, the present study was carried out in search for its bioactive chemical constituents. The methanolic extract and its various fractions were subjected to chromatographic separations that resulted in the isolation of two flavonoids for the first time from this plant. The structure elucidation and detailed biological evaluations of these compounds were then carried out and the results are presented in the present paper.

\section{Results and Discussion}

Compound 1 was purified from the ethyl acetate fraction in the form of a yellow colored amorphous powder. When the TLC plate was sprayed with ceric sulphate, it gave a yellow color, indicating the compound belongs to the flavone class. The presence of a flavonoid skeleton was also supported by UV maxima at 264 and $340 \mathrm{~nm}$ [10]. The IR absorptions were indicative of a hydroxyl functional group $\left(3599 \mathrm{~cm}^{-1}\right)$, aromatic functionalities $\left(2922,1591\right.$, and $\left.1463 \mathrm{~cm}^{-1}\right)$ and conjugated ketone $\left(1665 \mathrm{~cm}^{-1}\right)$ in the molecule. The EI-MS showed a molecular ion peak at $m / z 302\left[\mathrm{M}^{+}\right]$, along with the major fragments at $\mathrm{m} / \mathrm{z} 153$ and 149 . These fragments appeared as a result of the retro Diels-Alder (RDA) fragmentation of the $\mathrm{C}$ ring [11]. 
The ${ }^{1} \mathrm{H}-\mathrm{NMR}$ spectrum of 1 exhibited signals at $\delta 6.19$ and $6.36(\mathrm{~d}, J=2.0 \mathrm{~Hz})$ which were indicative of the presence of meta coupled protons. These signals were thus assigned to H-6 and H-8, respectively. H-3', H-5', and H-6', protons of ring B appeared at $\delta 7.33(1 \mathrm{H} \mathrm{d}, J=2.1 \mathrm{~Hz}), 6.90(1 \mathrm{H} \mathrm{dd}$, $J=2.1,8.1 \mathrm{~Hz}$ ), and $7.30(1 \mathrm{H} \mathrm{d}, J=8.1 \mathrm{~Hz})$ respectively (Figure 1).

Figure 1. Structures of compound 1 and 2.
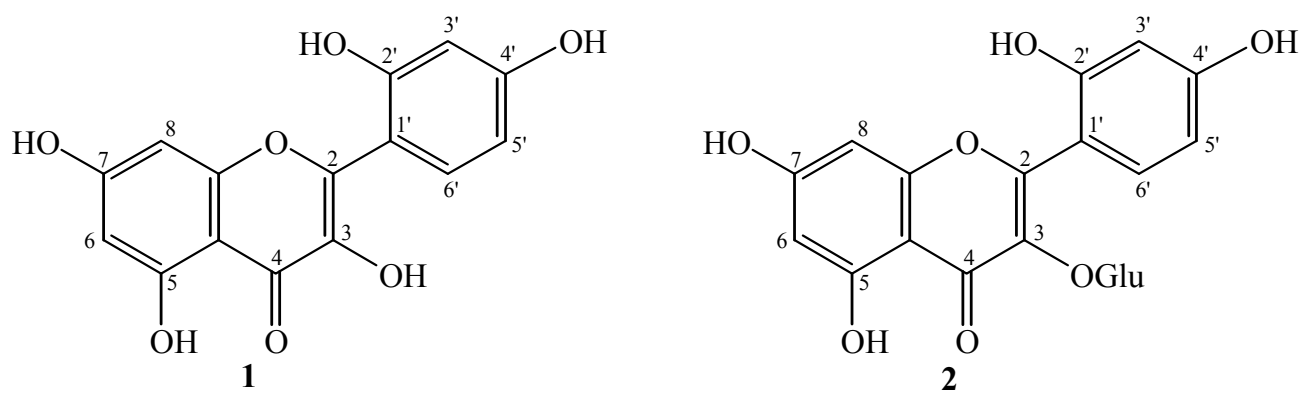

The ${ }^{13} \mathrm{C}$-NMR (BB and DEPT experiments) displayed ten quaternary and five methine carbons. The resonances at $\delta 99.8$ and 94.7 were assigned to C- 6 and C-8 respectively, while the ${ }^{13} \mathrm{C}-\mathrm{NMR}$ signals at $\delta 158.5,163.3$, and 163.2 were assigned to C-5, C-7, and C-9. These assignments indicated the ring A to be meta substituted with oxygenated groups [12]. The resonances at $\delta 149.8$ and 159.3 were assigned to $\mathrm{C}-2$ ' and $\mathrm{C}-4$ ' positions respectively, while the remaining ring $\mathrm{B}$ carbons appeared at $\delta 116.9$ (C-3'), $116.4\left(\mathrm{C}-5^{\prime}\right), 122.9\left(\mathrm{C}-6^{\prime}\right)$, and $122.8\left(\mathrm{C}-1^{\prime}\right)$. The proposed structure was finally confirmed by the comparative analysis of the reported data for morin to that of compound 1 [13].

Compound 2 was isolated from the ethyl acetate fraction by repeated silica gel column chromatography. The structure was determined by the analysis of ${ }^{1} \mathrm{H}$ and ${ }^{13} \mathrm{C}-\mathrm{NMR}$ data as well as by comparison with previously reported values $[14,15]$. MS showed a protonated molecular ion peak at $\mathrm{m} / \mathrm{z} 465.2039$ $[\mathrm{M}+1]^{+}$, suggesting the molecular formula $\mathrm{C}_{21} \mathrm{H}_{20} \mathrm{O}_{12}$. The fragment ion peak at $\mathrm{m} / z 303.3505$ appeared due to loss of a deoxyhexose group. The IR spectrum showed absorptions for $\mathrm{OH}$ groups at $3450 \mathrm{~cm}^{-1}$. The ${ }^{1} \mathrm{H}-\mathrm{NMR}$ spectrum showed three aromatic proton signals at $\delta 7.83\left(\mathrm{~d}, J=2.4 \mathrm{~Hz}, \mathrm{H}-3{ }^{\prime}\right), 6.87$ (dd, $\left.J=8.4,2.4 \mathrm{~Hz}, \mathrm{H}-5^{\prime}\right)$ and $6.86\left(\mathrm{~d}, J=8.4 \mathrm{~Hz}, \mathrm{H}-6^{\prime}\right)$ in the form of an ABD spin-system suggesting a flavonol with a $2^{\prime}, 4^{\prime}-$ disubstituted B-ring. Ring A protons appeared as a pair of meta coupled proton signals at $\delta 6.19(\mathrm{~d}, J=2.4 \mathrm{~Hz}, \mathrm{H}-6)$ and $6.39(\mathrm{~d}, J=2.4 \mathrm{~Hz}, \mathrm{H}-8)$.

The ${ }^{13} \mathrm{C}$-NMR spectra supported this proposed structure and showed 21 signals including a carbonyl signal at $\delta 179.5$ (C-4). It revealed chemical shifts at $\delta 135.7$ (C-3), 163.0 (C-5), 166.2 (C-7), 145.8 (C-3'), $149.9\left(\mathrm{C}-4^{\prime}\right)$ for the oxygenated quaternary carbon centers. The signals at $\delta 105.3$ (C-1"), 75.1 (C-2"), 77.2 (C-3"), 70.0 (C-4"), 73.1 (C-5"), and 61.9 (C-6") were assigned to the glucose moiety in the molecule.

Thus, on the basis of the above discussions compound 2 was identified as morin-3-O- $\beta$-Dglucopyranoside. The identity of this compound was further substantiated by comparison of its spectral data with previously reported values $[14,15]$.

\section{Anticancer, Allelopathic, Antifungal and Antioxidant Activities}

Three cancer cell lines: colorectal adenocarcinoma (HT29), colorectal adenocarcinoma (HCT116); and human hepatoma derived cell line (HepG2) were used to analyze the cytotoxic potential of compounds 1 and 2. Both the compounds were inactive against the HepG2, HCT116 and HT29 cancer 
cell lines at lower concentrations $(0.1$ to $50 \mathrm{ppm})$. However, when $100 \mathrm{ppm}$ concentration of compound 1 was applied to the HepG2, HT29 and HCT116, the cancer cells cell viability was reduced appreciably to $63.8 \%, 64.5 \%$, and $45.3 \%$, respectively. Contrarily, compound 2 suppressed the cell viability of HepG2, HCT116 and HT29 cell lines to $11.20,22.19$ and $38.11 \%$ as compared to control (Figure 2).

Figure 2. Anticancer cell activity of compounds 1 and 2. The bars represent the mean values with standard error of three replicates.

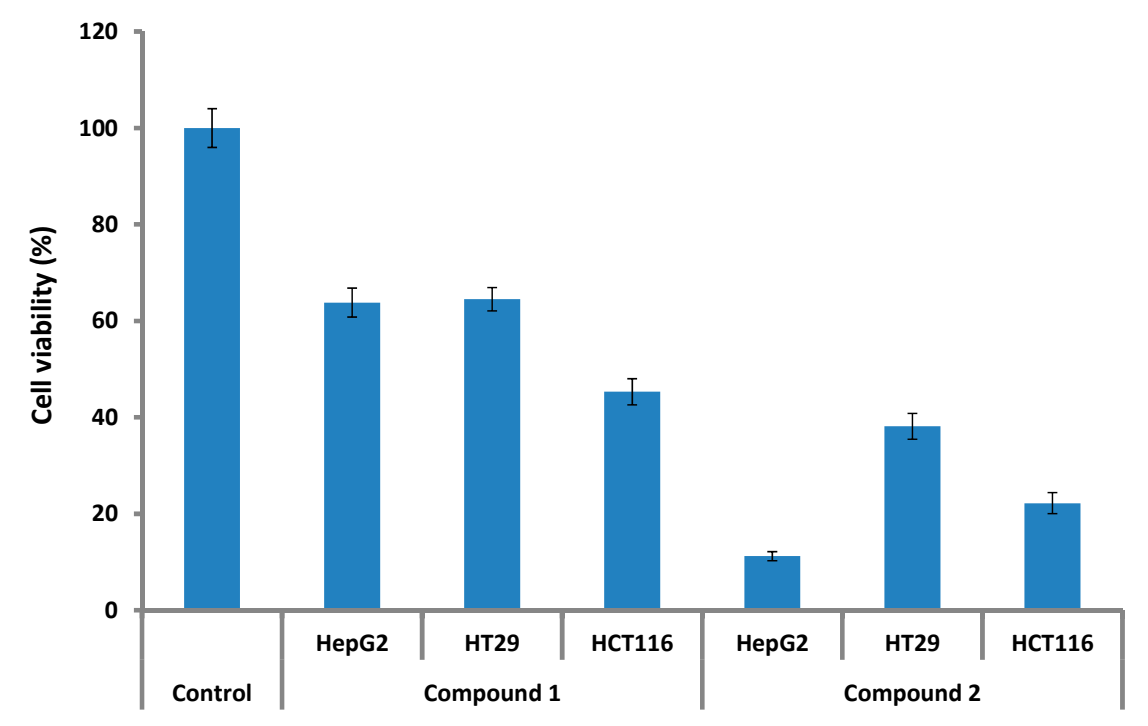

Flavonoids have been known to play an essential role in allelophathy as the plants release them through root exudation into the soil to safeguard it from pathogens and to act as food source for various soil microflora [16,17]. Both the compounds were also assessed for their allelopathic potential. Results showed that higher concentrations of 100 and $500 \mathrm{ppm}$ significantly inhibit the growth and germination of lettuce seeds (Figure 3), whereby 100 and $500 \mathrm{ppm}$ concentrations of compound 1 showed $\mathrm{EC}_{50}$ values of $49.21 \%$ and $33.82 \%$, respectively, while in case of compound 2 , the same concentrations showed $\mathrm{EC}_{50}$ values of $38.97 \%$ and $24.87 \%$, respectively. In the case of lower concentrations of 20 and $50 \mathrm{ppm}$ neither compound showed an $\mathrm{EC}_{50}$ value, however, the effects of these concentrations were significantly inhibitive to lettuce growth as compared to control. Overall, the compound application showed inhibitive effects on seed germination and growth. This result is in conformity to the effects of other flavonoids like 7,8-benzoflavone [16]. Such an effect is reported for the first time for compounds $\mathbf{1}$ and $\mathbf{2}$.

Compound $\mathbf{1}$ and $\mathbf{2}$ were also tested against known plant pathogens viz. Aspergillus niger, Fusarium oxysporum, Chaetomium globosum, and Alternaria alternata. The results showed that at 50 and $200 \mathrm{ppm}$ concentrations of compound 1, the fungi were actively growing, however, at $1000 \mathrm{ppm}$, compound 1 resulted in $17.21 \pm 0.21,16.87 \pm 0.93,19.437 \pm 0.57$ and $19.23 \pm 0.74 \mathrm{~mm}^{2}$ of growth of Aspergillus niger, Fusarium oxysporum, Chaetomium globosum, and Alternaria alternate, respectively (Figure 4). Previously, Alam and Edziri et al. [18,19] have reported that various kinds of flavones can inhibit the growth of pathogenic fungi. In the present results, higher concentrations of compounds $\mathbf{1}$ and 2 reduced the growth of pathogenic fungi, suggesting the exudation via the root from JOA is allelopathic and antifungal, especially to $F$. oxysporum. 
Figure 3. Allelopathic effects of compound $\mathbf{1}$ and $\mathbf{2}$ on the growth of lettuce seeds and pathogenic fungi; the bars represent the mean values with standard error of three replications. The different letter $(\mathrm{a}, \mathrm{b}, \ldots \mathrm{g})$ on each bar shows significantly $(p<0.05)$ different values as evaluated by DMRT analysis.

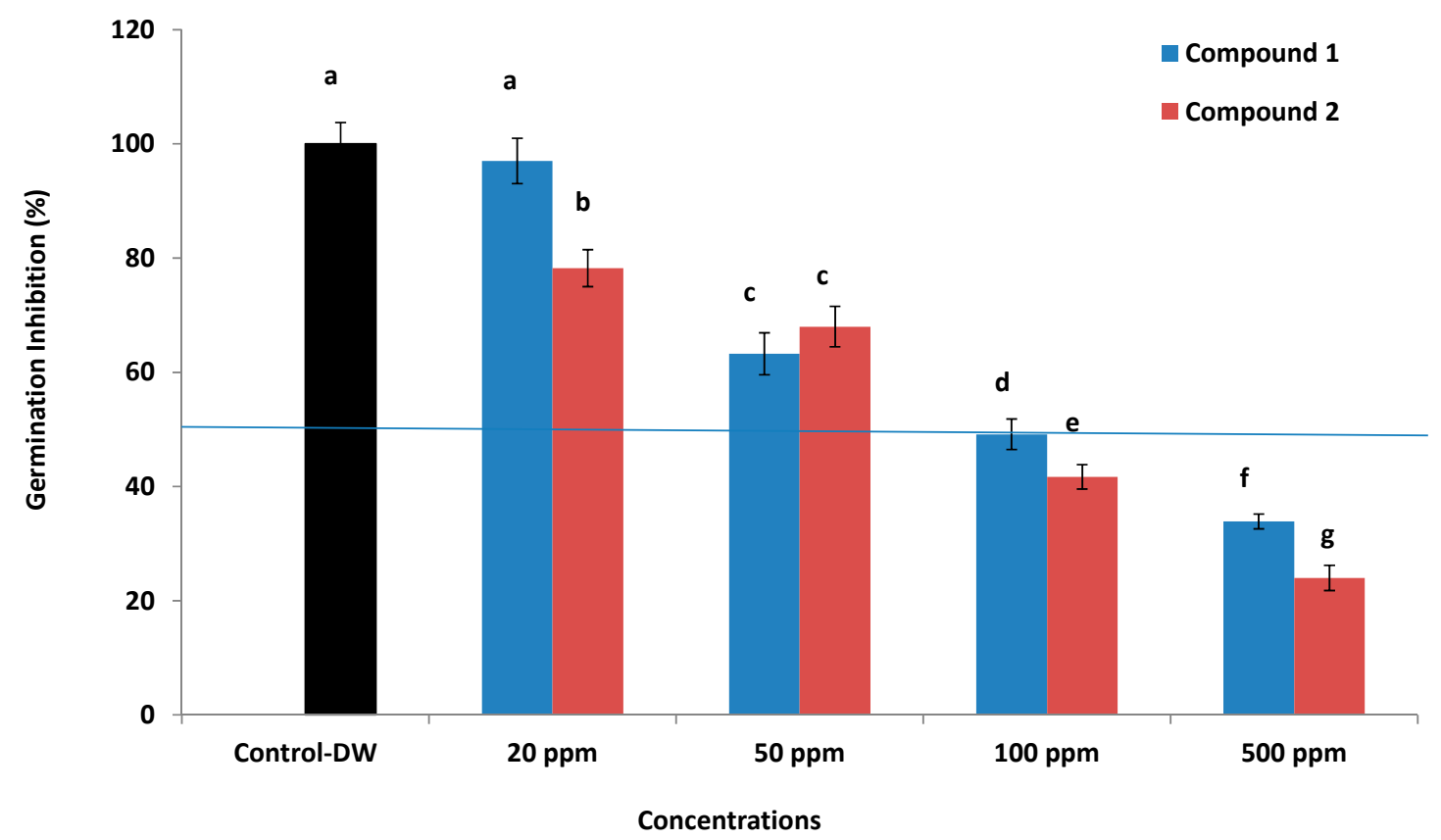

Figure 4. Antifungal activities of compound 1 and $\mathbf{2}$ against the growth pathogenic fungi. The bars represent the mean values with standard error of three replicates.

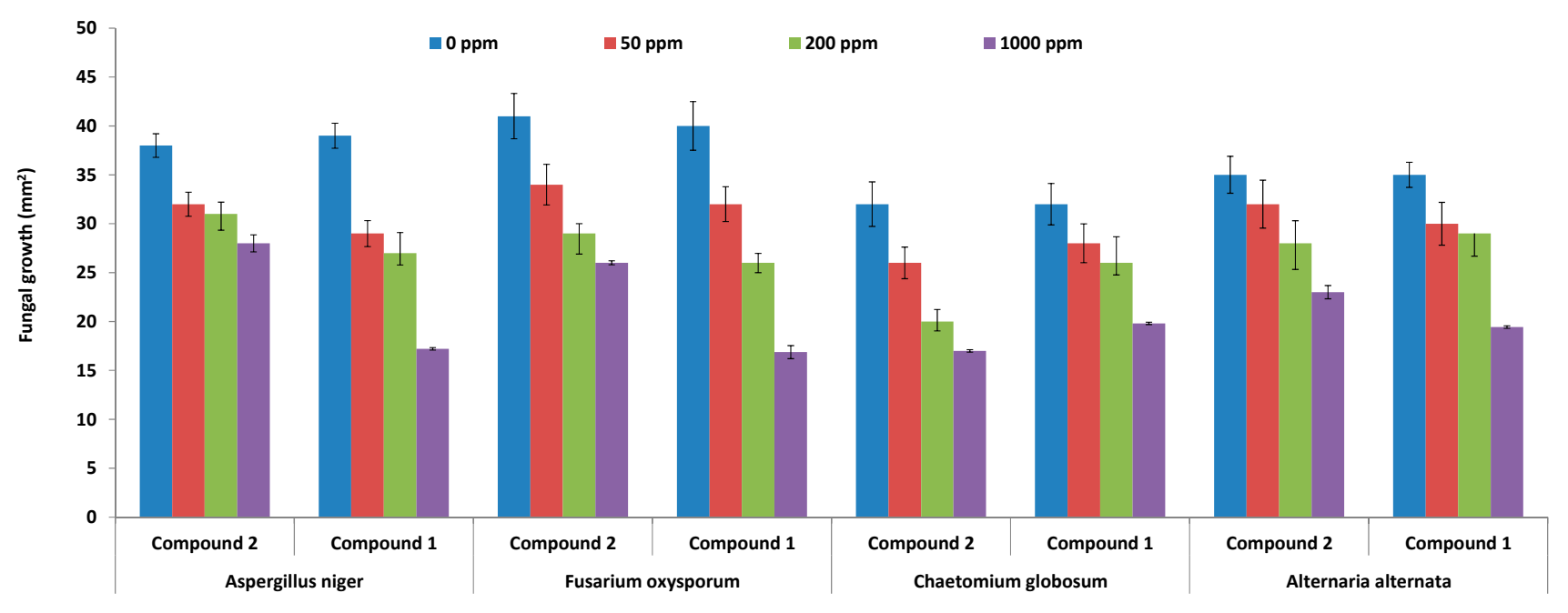

Both compounds were assessed for their potential antioxidant activities. The anti-lipid peroxidation results showed a very significant activity of compound $\mathbf{2}$ as compared with compound $\mathbf{1}$ (Table 1). Similarly, the potential of scavenging superoxide anion and DPPH radicals was significantly higher for compound $\mathbf{1}$ as compared to compound $\mathbf{2}$. This was in conformity with the known standard ascorbic acid and quercetin. Flavonoids have been known to ameliorate oxidative stress, which develops inside cells during disease exposure [19,20]. Our results with compounds $\mathbf{1}$ and $\mathbf{2}$ also showed a strong potential in this regard, however, in vivo analysis would be needed to further elucidate the roles of these flavonoids. 
Table 1. Antioxidant activities of isolated compounds.

\begin{tabular}{lccc}
\hline Compounds & Anti-Lipid Peroxidation (\%) & Superoxide Anion (\%) & DPPH (\%) \\
\hline Control & $92.34 \pm 0.023 \mathrm{a}$ & $64.19 \pm 0.73 \mathrm{a}$ & $98.88 \pm 0.92 \mathrm{a}$ \\
Compound $\mathbf{1}$ & $75.22 \pm 0.023 \mathrm{c}$ & $43.76 \pm 0.0042 \mathrm{~b}$ & $97.96 \pm 1.04 \mathrm{a}$ \\
Compound 2 & $81.58 \pm 0.12 \mathrm{~b}$ & $37.12 \pm 0.18 \mathrm{c}$ & $76.83 \pm 0.78 \mathrm{~b}$ \\
\hline \pm shows the standard error of means of three replications. The analyses were performed with comparative \\
standards. The different letter (a,b,c) in each column shows significant $(p<0.05)$ difference in the mean \\
values with respect to control by DMRT analysis.
\end{tabular}

Previously some reports have suggested that morin or related derivatives/constituents showed a diverse range of biological functions. These compounds have been known to play essential roles in suppressing the growth of cancerous cells as shown by Tian et al. [21]. Similarly, Jin et al. [22], showed that morin suppress the growth of breast cancer cell lines by influencing the Akt pathway. Although, the role of morin (1) is somehow understood in HepG cells, the activity of morin-3-O- $\beta$-Dglucopyranoside (2) has not been previously known. The morin flavonoids also showed inhibitory effects towards seed germination of lettuce. In present study, our results showed that $\mathbf{1}$ and $\mathbf{2}$ also exhibited a similar pattern of growth diminishing effects. Previously, Munesada et al. [23] showed that flavonoid glycosides showed inhibitive effects for lettuce seed germination. Our results are in conformity with the results of Alam and Edziri et al. [18,19], however, compound 2 has not been known for its role against pathogenic fungi. In addition to that compounds $\mathbf{1}$ and $\mathbf{2}$ were assayed for their role in the enzyme inhibition of reverse transcriptase, protein-tyrosine kinase and xanthine oxidase, whilst it also showed anti-HIV, antiarteriosclerotic, and superoxide scavenging activities [22,23]. The present anti-oxidative stress results also showed that $\mathbf{1}$ and $\mathbf{2}$ are promising antioxidant agents. Natural products with such diverse biological and ecological roles suggest a wide range of applications for the benefit of humans.

\section{Experimental Section}

\subsection{Plant Material}

The plant, Acridocarpus orientalis A. Juss (Malpighiaceae), was collected from Al-Hamra, in the Ad-Dakhiliyah region of the Sultanate of Oman in March-April 2012, and has been identified by a plant taxonomist at the Department of Biological Sciences and Chemistry, University of Nizwa, Nizwa, Sultanate of Oman. The voucher specimen has been deposited in the herbarium of the department.

\subsection{Extraction and Isolation}

The air-dried ground plant material (Acridocarpus orientalis, $4.1 \mathrm{~kg}$ ), was exhaustively extracted with $100 \%$ methanol $(8 \mathrm{~L})$ at room temperature. The extract was evaporated to yield a residue $(600 \mathrm{~g})$ that was partitioned in different solvents on the basis of increasing polarity to afford $n$-hexane ( $40.9 \mathrm{~g})$, chloroform ( $84.8 \mathrm{~g})$, ethyl acetate $(30.6 \mathrm{~g})$, and $n$-butanol $(58.3 \mathrm{~g})$ fractions. The ethyl acetate fraction (30 g) was subjected to column chromatography over a silica gel column (600 g, 70-230 mesh, Merck, Munich, Germany) using 10\% ethyl acetate $/ n$-hexane $(2 \times 500 \mathrm{~mL})$ with a $5 \%$ gradient of increasing polarity up to $100 \%$ ethyl acetate, then by the gradient of methanol $(1 \%, 2 \%, 5 \%, 10 \%, 20 \%$ and 
$40 \%$ ), and finally washed with 100\% methanol; twenty six fractions were thus collected. Two compounds were isolated using repeated column chromatography (flash silica gel, 230-400 mesh), and preparative TLC (silica gel 60 GF254), using ethyl acetate/ $n$-hexane mixtures of various polarities. Fraction no. 5, obtained using $50 \%$ ethyl acetate $/ n$-hexane was loaded on a silica gel column (flash silica 230-400 mesh) and eluted with gradients of ethyl acetate/n-hexane to purify compounds 1 [40.7 mg; methanol/chloroform (0.5:9.5)] eluted with $90 \%$ ethyl acetate/ $n$-hexane and compound 2 [26 mg; methanol/ethyl acetate (1.5:8.5)] eluted with 4\% methanol/ethyl acetate.

\subsection{Anticancer Activities}

Three cancer cell lines: colorectal adenocarcinoma (HT29), colorectal adenocarcinoma (HCT116); and human hepatoma derived cell line (HepG2) were used for testing the cytotoxicity of both compounds according to the method of Mosmann [24], and further modified by Kim et al. [25]. All cell lines were purchased from the ATCC (Manassas, VA, USA). Cell lines were cultured in Advanced DMEM supplemented with $10 \%$ inactivated NBCS and $5 \mathrm{mM} \mathrm{L}$-glutamine, and grown at $37{ }^{\circ} \mathrm{C}$ in a humidified atmosphere of $5 \% \mathrm{CO}_{2}$ in air. The results were generated from two independent experiments; each experiment was performed in triplicate by using a MTT [3-(4,5-dimethylthiazol-2-yl)-2,5diphenyltetrazolium bromide] colorimetric assay.

\subsection{Allelopathic and Antifungal Activities}

The allelopathic potential of both compounds was studied by the method of Khan et al. [26]. Lettuce seeds (Lectuca sativa) were used to indicate the seed growth inhibition. EC50 values were also calculated which is the effective concentration of an extract/compound that induces $50 \%$ of inhibition of the tested organism [27]. Four different concentrations of 20, 50, 100, and 500 ppm of compound were prepared by dissolving it in 5\% DMSO. A filter paper method was used. Fifteen lettuce seeds were placed on it and the dishes were sealed for incubation at $25{ }^{\circ} \mathrm{C}$ for $72 \mathrm{~h}$. The experiment was repeated three times with three replicates.

Fungal pathogens viz. Aspergillus niger, Fusarium oxysporum, Chaetomium globosum, and Alternaria alternate were procured from the Leibniz-Institute DSMZ (Braunschweig, Germany). Antifungal activity was screened using a well-diffusion method [28]. Fungal growth was assessed against individual concentrations. Potato dextrose agar (PDA) plates were autoclaved at $121^{\circ} \mathrm{C}$ for 15 min. Seven day-old fungal pads were grown on the PDA plates to serve as master plate and later as negative control. Two wells in each PDA plate were made by using a sterile weller. Three concentrations i.e., 50, 200 and $500 \mathrm{ppm}$ were prepared. The wells were loaded with different concentrations and fungal pads are transferred onto plates to assess the level of fungal growth inhibition. The plates were incubated for 5 days at $28{ }^{\circ} \mathrm{C}$. Negative controls containing no sample were prepared too. Three replicates were maintained for each experiment, while the experiment was repeated twice.

\subsection{Antioxidant Activities}

Antioxidant activity of both the compounds was determined using the 1,1-diphenyl-2-picrylhydrazyl (DPPH) radical scavenging activity assay as reported by Gulati et al. [29]. To DPPH (50 $\mu \mathrm{L}$ of 
$0.1 \mathrm{mM}$; in methanol), $50 \mu \mathrm{L}$ of compound (in a concentration range of 1.0 to $500 \mu \mathrm{g} / \mathrm{mL}$ ) was mixed and kept in the dark at room temperature for $60 \mathrm{~min}$. After incubation, the absorbance was recorded at $490 \mathrm{~nm}$. The results were compared with the positive control (ascorbic acid). The antioxidant activity was expressed as percentage $(\%)$ inhibition $=(\mathrm{Ac}-\mathrm{As} / \mathrm{Ac}) \times 100$; where $\mathrm{Ac}_{\mathrm{c}}$ is absorbance of control and As is the absorbance of sample. The potential of compounds to inhibit the extent of lipid peroxidation was assessed through a modified thiobarbituric acid reactive substances (TBARS) method [30]. This was based on the peroxidation of a liposome (phosphatidyl-choline $50 \mathrm{mg} / \mathrm{mL}$ ) induced by iron chloride $(200 \mu \mathrm{L}, 1 \mathrm{mM})$ containing potassium chloride $(300 \mathrm{mM})$ in the presence of both compounds $(50 \mu \mathrm{L})$. Peroxidation was initiated by ascorbate $(125 \mu \mathrm{L}$ with $0.16 \mathrm{mM})$ and the reaction mixture was incubated for $30 \mathrm{~min}$ at $37{ }^{\circ} \mathrm{C}$. A mixture of trichloroacetic acid $(0.75 \mathrm{~mL}$ with 1.5:1 (v:v)) and TBA $(0.38 \%)$ was added to the reaction mixture. It was kept in boiling water for 30 min until a pink color appeared. The production of TBARS, mainly malonaldehyde, as a secondary product of peroxidation, was measured at $535 \mathrm{~nm}$. A control without compound was used as blank. Inhibition was calculated using the expression (IP\%): $(1-\mathrm{At} / \mathrm{Ao}) \times 100$; where At and Ao are compound and control absorbance after incubation for $30 \mathrm{~min}$. The experiment was repeated three times. Superoxide radical scavenging activity was measured by reducing nitroblue tetrazolium (NBT) as reported by Hazra et al. [31]. The non-enzymatic phenazine methosulfate-nicotinamide adenine dinucleotide (PMS/NADH) system generates superoxide radicals, which reduce NBT to a purple formazan. The $1 \mathrm{~mL}$ reaction mixture contained phosphate buffer $(20 \mathrm{mM}, \mathrm{pH} 7.4)$, NADH $(73 \mu \mathrm{M})$, NBT $(50 \mu \mathrm{M})$, PMS $(15 \mu \mathrm{M})$ and compounds $(20 \mu \mathrm{g} / \mathrm{mL})$. After incubation for $5 \mathrm{~min}$ at room temperature, the absorbance at $562 \mathrm{~nm}$ was measured against blank to determine the quantity of formazan generated. All tests were performed three times. Quercetin was used as positive control.

\section{Conclusions}

Local communities of the Arabian region have used Acridocarpus orientalis for medicinal purposes. This suggests the presence of bioactive chemical constituents. We isolated and identified two flavonoids: morin (1) and morin-3-O- $\beta$-D-glucopyranoside (2) from the methanolic extract. The compounds showed antifungal, phytotoxic, anticancer and anti-lipid peroxidation properties.

\section{Acknowledgments}

The authors would like to thank The Oman Research Council (TRC) for financial support under the Open Research Program Grant (ORG/CBS/12/004).

\section{Author Contributions}

JH, LA, NR, FJ and ALK designed and performed all the experiments. JSK performed the anticancer activities. JH, LA and AA wrote the article. All authors read and approved the final manuscript.

\section{Conflicts of Interest}

The authors declare no conflict of interest. 


\section{References}

1. Bako, S.P.; Bakfur, M.J.; John, I.; Bala, E.I. Ethno-medicinal and phytochemical profile of some savanna plant species in Nigeria. Int. J. Bot. 2005, 1, 147-150.

2. Williams, R.J.; Spencer, J.P.E.; Rice-Evans, C. Flavonoids: Antioxidants or signalling molecules? Free Radic. Biol. Med. 2004, 36, 838-849.

3. Soobrattee, M.A.; Neergheen, V.S.; Luximon-Ramma, A.; Aruoma, O.; Bahorun, T. Phenolics as potential antioxidant theraputic agents: Mechanism and actions. Mutat. Res. 2005, 579, 200-213.

4. Kisksi, T.; Guenaoui, C.; Fawzi, N. Early growth stages of the rare Acridocarpus orientalis in the UAE-A First step towards conservation. Nat. Resour. 2012, 3, 1-5.

5. Ksiksi, T.; Hamza, A.A. Antioxidant, lipoxygenase and histone Deacetylase inhibitory activities of Acridocarpus orientalis from Al Ain and Oman. Molecules 2012, 17, 12521-12532.

6. Monthana, R.A.; Lindequist, U.; Gruenert, R.; Bednarski, P.J. Studies of the in vitro anticancer, antimicrobial and antioxidant potentials of selected Yemeni medicinal plants from the island Soqotra. BMC Complement. Altern. Med. 2009, 9, 7, doi:10.1186/1472-6882-9-7.

7. Hammiche, V.; Maiza, K. Traditional medicine in central sahara: Pharmacopoeia of Tassili N'ajjer. J. Ethnopharmacol. 2006, 105, 358-367.

8. Malebo, H.M.; Tanja, W.; Cal, M.; Swaleh, S.A.M.; Omolo, M.O.; Hassanali, A.; Séquin, U.; Hamburger, M.; Brun, R.; Ndiege, I.O. Antiplasmodial, anti-trypanosomal, anti-leishmanial and cytotoxicity activity of selected Tanzanian medicinal plants. Tanzan. J. Health Res. 2009, 11, 226-234.

9. Ghazanfar, S.A. Herbal medicines and practices in northern Oman. In Proceedings of the III International Congress on Traditional Asian Medicine, Bombay, India, 4-7 January 1990; p. 509.

10. Toker, G.; Memisoglu, M.; Yesilida, E.; Aslan, M. Flavonoids of Tilia argentea Desf. ex DC. Leaves. Turk. J. Chem. 2004, 28, 745-750.

11. Branco, A.; Pinto, A.C.; Ifa, D.R.; Branz-Filho, R. Two $8 C$-methylated flavonols from the leaves of Vellozia candida Mikan (Velloziaceae). J. Braz. Chem. Soc. 2002, 13, 318-323.

12. Markham, K.R.; Chari, V.M.; Mabry, T.J. The Flavonoids: Advances in Research; Harbone, J.B., Mabry, T.J., Eds.; Chapman and Hall: London, UK, 1982.

13. Mabry, T.J.; Markham, K.R.; Thomas, M.B. The Systemic Identification of Flavonoids; Springer Verlag: New York, NY, USA; Heidelberg/Berlin, Germany, 1970.

14. Tachakittirungrod, S.; Ikegami, F.; Okonogi, S. Antioxidant active principles isolated from Psidium guajava grown in Thailand. Sci. Pharm. 2007, 75, 179-193.

15. Agarwall, P.K. 13C-NMR of Flavonoids; Elsevier: Amsterdam, The Netherlands, 1989.

16. Alford, É.R.; Vivanco, J.M.; Paschke, M.W. The Effects of flavonoid allelochemicals from Knapweeds on legume-rhizobia candidates for restoration. Restor. Ecol. 2009, 17, 506-514.

17. Weston, L.A.; Mathesius, U. Flavonoids: Their Structure, biosynthesis and role in the Rhizosphere, including allelopathy. J. Chem. Ecol. 2013, 39, 283-297.

18. Alam, S. Synthesis, antibacterial and antifungal activity of some derivatives of 2-phenyl-chromen4-one. J. Chem. Sci. 2004, 116, 325-331. 
19. Edziri, H.; Mastouri, M.; Mahjoub, M.A.; Mighri, Z.; Mahjoub, A.; Verschaeve, L. Antibacterial, antifungal and cytotoxic activities of two flavonoids from Retama raetam flowers. Molecules 2012, 17, 7284-7293.

20. Cotelle, N. Role of Flavonoids in Oxidative Stress. Curr. Top. Med. Chem. 2001, 1, 569-590, doi:10.2174/10569.

21. Tian, X.; Yang, X.; Wang, K.; Yang, X. The efflux of flavonoids Morin, isorhamnetin-3-Orutinoside and diosmetin-7-O- $\beta$-D-xylopyranosyl-(1-6)- $\beta$-D-glucopyranoside in the human intestinal cell line Caco-2. Pharm. Res. 2006, 23, 1721-1728.

22. Jin, H.; Lee, W.S.; Eun, S.Y.; Jung, J.H.; Park, H.S.; Kim, G.; Choi, Y.H.; Ryu, C.H.; Jung, J.M.; Hong, S.C.; et al. Morin, a flavonoid from Moraceae, suppresses growth and invasion of the highly metastatic breast cancer cell line MDA-MB-231 partly through suppression of the Akt pathway. Int. J. Oncol. 2014, 45, 1629-1637.

23. Munesada, K.; Siddiqui, H.L.; Suga, T. Biologically active labdane-type diterpene glycosides from the root-stalks of Gleichenia japonica. Phytochemistry 1992, 31, 1533-1536.

24. Mosmann, T. Rapid colorimetric assay for cellular growthand survival: Application to proliferation and cytotoxicity assays. J. Immunol. Methods 1983, 65, 55-63.

25. Kim, S.C.; Park, S.J.; Lee, J.R.; Seo, J.C.; Yang, C.H.; Byun, S.H. Cytoprotective activity of Glycyrrhizae radix extract against arsenite-induced cytotoxicity. Evid. Based Complement. Altern. Med. 2008, 5, 165-171.

26. Khan, A.L.; Hussain, J.; Hamayun, M.; Kang, S.M.; Watanabe, K.N.; Lee, I.J. Allelochemical, Eudesmane-Type Sesquiterpenoids from Inula falconeri. Molecules 2010, 15, 1554-1561.

27. Hiradate, S.; Morita, S.; Sugie, H.; Fujii, Y.; Harada, J. Phytotoxic cis-cinnamoyl glucosides from Spiraea thunbergii. Phytochemistry 2004, 65, 731-739.

28. NCCLS. Reference Method for Broth Dilution Antifungal Susceptibility Testing of Filamentous Fungi. Approved Standard M38-A; National Committee for Clinical Laboratory Standards: Wayne, PA, USA, 2002.

29. Gulati, V.; Harding, I.H.; Palombo, E.A. Enzyme inhibitory and antioxidant activities of traditional medicinal plants: Potential application in the management of hyperglycemia. BMC Complement. Altern. Med. 2012, 12, 77.

30. González-Montelongo, R.; Lobo, M.G.; González, M. Antioxidant activity in banana peel extracts: Testing extraction conditions and related bioactive compounds. Food Chem. 2010, 119, 1030-1039.

31. Hazra, B.; Biswas, S.; Mandal, N. Antioxidant and free radical scavenging activity of Spondias pinnata. BMC Complement. Altern. Med. 2008, 8, 63, doi:10.1186/1472-6882-8-63.

Sample Availability: Samples of the compounds $\mathbf{1}$ and $\mathbf{2}$ are available from the authors.

(C) 2014 by the authors; licensee MDPI, Basel, Switzerland. This article is an open access article distributed under the terms and conditions of the Creative Commons Attribution license (http://creativecommons.org/licenses/by/4.0/). 